\title{
İzmir Kemeraltı Kültürünü Haritalamak*
}

\author{
Gökçeçiçek SAVAŞIR**
}

Savaşır, G. (2020). İzmir Kemeraltı Kültürünü Haritalamak. YEDİ, 23, 59-73, doi: 10.17484/yedi.623067

Araştırma Makale / Research Article

özet

İzmir kentinin her noktasında geçmişten günümüze hissedilen çok renkli kent kültürünün tanıklık mekânlarının başında Kemeraltı gelmektedir. Makale İzmir kent kimliği ve kültürünün önemli bir parçası olan Kemeraltı özelinde mimarlık, sanat, zanaat, moda, tekstil gibi tasarım alanların somut ve soyut değerlerini odağına alan bir tasarım kültürü haritalama pratiğini konu alır. Çalışma, konuya ilişkin güncel yazına katkıda bulunmanın yanı sıra, Kemeraltı'na odaklanan bu haritalama pratiğini, kültür turizminin ve kentsel turizmin önemli araçlarından kent kültürünün haritalanması çerçevesinden irdelemeyi amaçlanmaktadır. Yorumlayıcı (interpretive) bir araştırma yöntemiyle ele alınan çalışmanın kapsamı, turizm ve mimarlık alanlarındaki kültürel miras, koruma, sürdürülebilirlik tartışmalarından farklılaşarak, yeni kentsel-kültürel turizm faaliyetleri ve tasarım kültürünün haritalanması konularıyla sınırlandırılmıştır. Bu kültürel haritalamanın Türkiye’de benzer kapsam ve nitelikteki alternatif haritalama pratiklerinin oluşturulması ve irdelenmesi için zemin oluşturacağı düşünülmektedir.

Anahtar Sözcükler: Kültür turizmi, kentsel-kültürel haritalama, kültür-tasarım yürüyüş rotaları, Kemeraltı, İzmir.

\section{Mapping the Culture of Izmir Kemeraltı}

\section{Abstract}

Kemeralti is one of the most important places of witnessing with multicolored urban culture that has been felt from past to present in every point of İzmir city. The article dwells on a cultural mapping practice that focuses on the tangible and intangible values of design areas such as architecture, art, craft, fashion and textile in the context of Kemeralt, which is an important part of İzmir city identity and culture. In addition to a contribution to the current literature on this subject, it aims to scrutinize this mapping from within the framework of cultural mapping as an important tool of cultural tourism and urban tourism. Differing from the debates on cultural heritage, conservation, or sustainability in the realms of tourism and architecture, the scope of the discussion is limited to new urban cultural tourism practices and mapping of design culture, while it is elaborated through an interpretive research method. It is believed that this cultural mapping will provide a basis for investigating alternative mapping practices with similar scope and quality in Turkey.

Keywords: Cultural tourism, urban-cultural mapping, cultural-design walking routes, Kemeraltt, Izmir. 


\section{Giriş}

Kültür, bir halkın ya da toplumun parçası olan bireylerin üyesi olduğu toplumdan öğrendiği bilgi, gelenek, görenek, davranış, yasa, sanat, uygulama, zanaat gibi tarihsel, toplumsal gelişme süreci içinde yaratılan ve sonraki nesillere aktarılan maddi ve manevi değerlerden oluşan bütündür (Türk Dil Kurumu, t.y.). Bu tanımdan hareketle kültür denildiğinde, maddi ve manevi değerlerin nesiller boyunca sürekliliğinden, doğal/toplumsal bütünlüğünden bahsedilebilir. Bu bütünlüğü oluşturan değerlerin karşılıkları olan, somut/soyut ürünler; duyuş, düşünüş, yaşayış bakımından diğer bütünlüklerden ayrışırlar. Somut/soyut kültürel değerler, zaman-mekânsal ilişkilerden oluşan karmaşık bir örüntü içinde var olur: Zamansal paydaşlıklar, farklı mekânlarda da olsa dönemin ruhunu yansıtan süreklilikleri görünür kılarken; mekânsal paydaşlıklar, farklı zamanlara ilişkin ipuçlarını ve mekândaki zamanlar-arası süreklilikleri ortaya çıkarır. Zaman-mekânsal örüntülerin ana sahnesi, tüm somut/soyut varlıklarıyla birlikte kenttir. Kent kültürü, bir kentte yaşayanların kolektif olarak ürettikleri somut ve soyut değerler toplamının zamanmekânsal anlamda oluşum sürecini ifade eder; bu paydaşlıklar arası sürekliliğe temellenir. Kent kültürünün oluşumunda, üretilen değerlerin kentliler tarafından ortak bir anlam ifade ediyor olmasının yanı sıra, kente ilişkin kolektif bir belleğin sürdürülmesi de önemlidir.

Kültür turizmi, yirminci yüzyıl sonunda sağlık, kongre, ekoloji vb. odaklı alternatif turizm biçimleri gibi sektörün önemli bir parçası haline gelmiştir (Aksatan, 2014, s.31). Ekoturizm, kruvaziyer seyahati, tematik turizm yanı sıra kültür turizmi, Dünya Turizm Örgütü’nün (WTO) 2020 Vizyon Çalışması'nda en popüler turizm biçimleri olarak saptanmış (Tourism at world heritage sites, 2013); küresel ve ulusal ölçeklerde özellikle 2000’li yıllardan itibaren popüler hale gelmiştir. Dolayısıyla, kültür ve kent kültürü odaklı geziler aracılığıyla zaman-mekânsal deneyimler çoğalmış; söyleşilerle ya da rehber kitaplarla bilgilerin paylaşımı yaygınlaşmıştır.

Bir turizm şehri olan İzmir için de, son yıllarda doğal varlıklar yerine kültürel değerlerin turizm açısından ön plana çıktığı görülmektedir. 2011 yılında yayınlanan ve İzmir kültür turizmi için tespitler yaparak öneriler sunan raporda, kültür turizminin kapsamı şu şekilde açıklanmaktadır:

Tüm kentsel, kırsal, doğal öğeler, arkeolojik, tarihsel kültür varlıkları, müzeler, ören yerleri, anıtsal yapılar, sivil mimari örnekleri ve her türlü güncel sanat eseri ve etkinliği (resim, heykel, film, fotoğraf, güncel sanat etkinlikleri, festivaller, konserler, sergiler) etnografya, botanik, flora ve fauna, folklor, mutfak, içki, bazı sosyoekonomik olgular (gecekondular, sivil toplum kuruluşları, dinsel motifler, değişik study tours konuları), her türlü kültür ürünü, böcekçilik, kuşçuluk, ipek yolu turizmi, kruvaziyer turizmi, eko-turizm, trekking gibi alternatif spor turları, doğrudan Hac seferleri dişındaki inanç turizmi, özel temalı turlar, çalışma turları, coğrafi ya da eğitimsel turlar, kongre, fuar, sergi ve sağlık turizminin turları (Ege Derneği, 2011).

T.C. Kültür ve Turizm Bakanlığı, İzmir İl Kültür ve Turizm Müdürlüğü'nün resmi web sayfasında da İzmir'in genellikle doğal ve tarihi değerlerine odaklanan turizm potansiyelinde, vurgunun daha çok kültürel değerlere yapıldığı görülmektedir: Deniz, güneş, kum üçlüsünün yanı sıra, kent merkezinde antik dönemden beri varlığını korumuş olan Kadifekale, dünyanın bilinen en büyük antik agoralarından birisi olan Smyrna Agorası kendine has dokusuyla mistik bir atmosfere sahip Kemeraltı Çarşısı, Saat Kulesi, camileri, kiliseleri, havraları, hanları, çeşmeleri, tarihi köşkleri, kendine özgü mimari dokusuyla Alsancak semti kültür turizmi yönünden şehrin önemli çekicilikleridir. Ayrıca yöresel kültürü, el sanatları, geleneksel mutfağı, ulusal ve uluslararası kültür-sanat etkinlikleri ve diğer kültürel değerleri ile İzmir yaygın olarak kültür turizminin gerçekleştirildiği bir destinasyondur. İlimizde gerek bireysel olarak, gerekse seyahat acentaları kanalıyla gelen turistler için pek çok kültür turu imkânları mevcuttur (Kültür Turizmi, 2018).

Bilinen 8500 yıllık köklü tarihinde farklı uygarlıklara, gelenek ve göreneklere ev sahipliği yapmış olan İzmir, tarih boyunca Doğu Akdeniz'in en önemli liman kentlerinden biri olması dolayısıyla ticari, sosyal ve kültürel alışverişin en hareketli mekânlarından biri olagelmiştir. Geçmişten günümüze, kentin her noktasında hissedilen çok renkli kent kültürünün tanıklık mekânlarının başında Kemeraltı gelmektedir. Tarih boyunca ticari ve kültürel odak olan Kemeraltı, Mezarlıkbaşı semtinden Konak Meydanı'na ve Tarihi Agora'dan Basmane Garı'na kadar, iki bölgeden oluşmaktadır (Ecemiş Kılıç ve Aydoğan, 2006). Kemeraltı, adını 15.000 ticarethaneye ev sahipliği yapan, kapalı ve açık mekânlardan oluşan tarihi çarşıdan alır (Tarihi Kemeraltı Çarşısı, t.y.). Çarşıda, geleneksel Türk el sanatlarının her çeşidini bulmak mümkündür (Kemeraltı, t.y.). Kemeraltı, tarihi 
agora, camiler, kiliseler, sinagoglar, çeşmeler, kervansaraylar, oteller, Türk hamamları gibi nitelikli taşınmaz varlıklarıyla hem somut kültürel değerlerin; hem de hareketli, renkli, canlı deneyimler, usta-çırak ilişkileriyle süregelen geleneksel üretim biçimleri, modern yaşam pratikleri gibi somut olmayan kültürel değerlerin taşıyıcısıdır ${ }^{1}$. UNESCO listesinde yer alan el sanatları geleneğinin korunması konusunda Kemeraltı'nın aday gösterilmesi gündeme getirilmiştir (Kemeraltı dünya mirası olsun, t.y.). Kent içi turizminin ana ekseninde yer alan Kemeraltı, mimarlık, zanaat, moda ve gastronomi gibi tasarımın farklı alanlarının da beslendiği bir merkezdir.

Kemeraltı, İzmir kent merkezinin tarihi ticari odağı olarak kent kültürünün sürdürülebilirliğinde önemli bir role sahiptir. Son yirmi yıldır gündeme gelen kentsel yenileme ve canlandırma süreçlerinde, bu alanın tarihsel, kültürel ve toplumsal değerlerinin nasıl korunacağı üzerine çalışmalar yürütülmektedir. Özgün tarihi, toplumsal ve kültürel kimlikler, mevcut alan kullanımlarının değiştirildiği, ulaşımla ilgili düzenlemelerin yapıldığı, yapısal dönüşümlerin gerçekleştirildiği 21. yüzyılın neoliberal kentsel yenileme ve canlandırma uygulamalarının pek çoğunda, bu süreçlerde kaybolmaktadır. Hatta motivasyonunu çoğunlukla ticari önceliklerin belirlediği küresel kentsel stratejilerden sayılan soylulaştırma süreçlerinde (Smith, 2006), alanın düşük gelirli sakinleri yerlerini zamanla, yeni ve şık mekânların daha yüksek gelirli sahiplerine terk etmek zorunda kalmaktadırlar.

Makalenin temel savı, kapsam, içerik ve yöntem açısından kendi dışındaki üretim alanlarıyla ilişkilendirilmeden gerçekleştirilen her çalışmanın, Kemeraltı'nın çok boyutlu kültürünü tam olarak yansıtamayacağı düşüncesine dayanır. Çok katmanlı yapısıyla Kemeraltı'na ilişkin bilgiler, hem düşünsel hem de pratik düzlemlerde, çok-disiplinliçalışmalarla üretildiğinde daha anlamlı olacaktır. Bu motivasyona temellenen makalenin odağını, İzmir Kemeraltı'nın mimarlık, sanat, zanaat, moda, tekstil gibi farklı üretim alanların somut ve soyut değerlerinin tasarım kültürü üst başlığında bütüncül olarak ele alındığı bir haritalama pratiği oluşturur. Planlama, kültürel planlama, kentsel tasarım gibi farklı disiplinler tarafından da kullanılmakla birlikte, burada kentsel-kültürel haritalama, kültür turizminin bileşenlerinden biri olan kentsel turizmin önemli araçlarından biri olarak kabul edilmiştir.

1 Birleşmiş Milletler Eğitim Bilim ve Kültür Teşkilatı UNESCO, 2003 yılında temel amacı kültürel mirası korumak olan Somut Olmayan Kültürel Mirasın Korunması Sözleşmesi'ni kabul etmiş ve Türkiye 2006 yılında sözleşmeye taraf olmuştur (UNESCO somut olmayan kültürel miras, t.y).
Makale, İzmir Kemeraltı’nın tasarım kültürünün haritalanması pratiğini, kültür turizmi ve kentsel-kültürel haritalama kavramları çerçevesinden irdelemeyi amaçlamaktadır.

Nitel araştırma evrenine ait yöntemlerinden biri olan yorumlayıcı (interpretive) araştırma, toplumsal gerçekliklerin ontolojik olarak insan deneyimleri ve toplumsal bağlamlarla şekillendiği; dolayısıyla epistemolojik olarak tarihsel ve toplumsal bağlamların içinden, katılımcılarının öznel yorumlamalarının uzlaşısı ile bulunabileceğine temellenir. Yorumbilimin önemli düşünürlerinden Hans Georg Gadamer, gerçek araştırma şekli ve düşünme sanatı olarak gördüğü diyalog ile yakın iletişimi sürdürme sanatı olan şeklinde sorgulamayı tartışmaya açar (Gadamer, 1979). Benzer bakışla, bu çalışmanın konusunu oluşturan haritalama pratiğinde tekrar tekrar okunan bir metin gibi yeniden keşfedilen yer (Kemeraltı) ile haritalama pratiğini gerçekleştiren çalışma ekibinin 'anlama-yorumlama-uygulama' eksenindeki diyaloğu önemsenmiştir: Her iki tarafın da karşılıklı olarak birbirinin sınırlarını belirlediği bu diyalog, Kemeraltı'nın aşinalığı ve yabancılığına dayanan gerilim ile birlikte, bu kültürel haritalama pratiğinin rastlantısal bir şartı değil, araştırma ve keşfin kendisi olarak düşünülmüştür. Bu makalenin yazarı, aynı zamanda haritalama pratiğinin aktörlerinden biridir. Yorumlayıcı (interpretive) araştırma yöntemiyle ele alınan makalede, bu haritalama pratiği kültür turizmi ve tasarım kültürünün haritalanması çerçevesinden irdelenmektedir.

Makalenin kapsamı turizm ve mimarlık alanlarındaki kültürel miras, koruma, sürdürülebilirlik gibi tartışmalardan farklılaşarak, yeni kentsel-kültürel turizm faaliyetleri ve tasarım kültürünün haritalanması paydasında sınırlandırılmıştır. Tasarım kültürü haritalama çerçevesinde ele alınan makalenin, benzer kapsam ve nitelikteki alternatif çalışmaları oluşturmaya ve irdelemeye zemin oluşturacağ ön görülmektedir. Kemeraltı'nın tasarım kültürünün haritalanması ya da bu haritalama pratiğinin olası ürünleri olan yürüyüş rotaları ya da rehberler üzerine turizm ve/ veya tasarım disiplinlerinde lisansüstü düzeyde akademik çalışmalar yapılması ilgili yazına katkıda bulunacaktır.

\section{Kavramsal Çerçeve}

Kültür, “insanların ne düşündükleri (tutumlar, inançlar, fikirler ve değerler), insanların ne yaptıkları (normatif davranış kalıpları veya yaşam tarzları) ve insanların neler ortaya koydukları (sanat eserleri, sanat eserleri, kültürel ürünler)” olarak tanımlanmaktadır (Littrell'in makalesinden 
aktaran, Richards, 2003, s.6). Dolayısıyla, kültür insanların fikirleri ve yaşam biçimlerini kapsayan süreçler ile binalar, sanat eserleri, gelenekler gibi bu süreçlerin ürünlerinden oluşur. Bu anlamda kültür turizmi; kültür varlıklarını, kültürel etkinlikleri, güncel sanat eserlerini ve sosyo-ekonomik olguları da içeren kültürel faaliyetleri temel alır; 'geleneksel' turizm bakış açısı ile sadece ziyaret edilen yerleri ve anıtları değil; ziyaret edilen yerlerdeki yaşam tarzının da deneyimlenmesini hatta tüketilmesini de kapsar (Richards, 2003, s.4-6). Bu nedenle kültür turizmi insanların, kültürel gereksinimlerini karşılamak üzere yeni bilgi ve deneyim toplamak gayesiyle yaşadıkları yerden uzaklaşarak, kültürel çekim merkezlerine gitmeleri olarak tanımlanabilir (Richards, 1996, s. 23). Kişilerin, tarihsel, güncel ve kültürel değerlere ilişkin yeni bilgi ve deneyim edinmek üzere gerçekleştirdikleri turizm hareketlerini ifade eden kültür turizmi için kültürel miras önemli bir bileşendir. Geçmişten günümüze, toplumun temel özelliklerini ve geleneğini yansıtan somut ve somut olmayan değerler, kültürel miras olarak kabul edilir (Timothy ve Boyd, 2001; UNESCO database of national cultural heritage laws, 2003). Kültürel miras gelişmiş ekonomilerin birçoğunda belirgin ve hızlı gelişen bir turizm bileşeni olarak kabul edilmektedir ( $\mathrm{Li}$, Wu ve Cai, 2008; Loulanski ve Loulanski, 2011; Poria, Butler ve Airey, 2003).

Günümüz turizm taleplerinde, arayışlar istisnai olandan gündelik olana kaymış; kültür turizminin faaliyet alanlarından biri olan kentler ve gündelik hayatın sürüp gittiği kent mekânları, ziyaretçilerin yerel halkla ve onların sıradan aktiviteleriyle daha sık kesiştiği, o kente özgü gündelik hayat pratiklerini deneyimledikleri, bu kentsel deneyim aracılığıyla kendi öznel hikâyelerini oluşturabildikleri çekim noktaları olarak kabul edilmeye başlanmıştır. Öte yandan kentli, yerel halk, ya da sıradan insan için yaşadığı kentin turizm ve eğlence ekseninde şekillenen cazibesinin aktif kurucu öğelerinden biri haline gelmiştir. Kültür turizminin ziyaret eden öznesi olan birey, ziyaret ettiği kent mekânlarında yürürken yeni bilgiler edinir ya da oradaki gündelik hayata kısmi de olsa dâhil olarak kentin kültürünü deneyimler. Kültür turizminde gitgide daha önemli hale gelen bu yeni bakışın, kentsel mekân, gündelik hayat, mekânın üretimi gibi kavramlar aracılığıyla bir arada düşünülmesi konuya farklı boyutlar ekleyecektir.

Modern kent kuram ve pratiklerinin, gündelik hayatı eleştirel teorinin merkezine oturtarak alternatif sunan Fransız felsefeci, sosyolog ve kentbilimci Henri Lefebvre gündelik hayatı çağdaş endüstri, teknoloji ve tüketim toplumu üzerinden irdelerken, "bütün farklılıkları ve çatışmalarıyla tüm faaliyetleri kapsayan, buluşturan ve bağlayan ortak zemin" olarak tanımlar (Lefebvre, 1991a, s.97). Lefebvre haz mimarlığını, turizm alanları üzerinden tartışmaya açar; keşfetmek, kurmak, keyifli mekânların izini sürmek, anlamak, tariflemek ve üretmek için, duyular ve bedenin imkânlarını araştırır; yaşanan deneyimi merkeze alarak kavramsallaştırır; kentteki bireylere ve gündelik hayat içindeki sıradan insanlara da aktif rol biçer (Lefebvre, 2014, s.152). Lefebvre "somut soyutlamalar olan toplumsal ilişkiler, mekânda karşılık bulan gerçek bir varlığa sahip değildir” sözleriyle, toplumsal, mekânsal ve zamansal üç öğenin birbirlerini biçimlendirdiğini; toplumsal olanın, tarihsel-mekânsal olarak ve benzer şekilde, mekânsal olanın, tarihsel-toplumsal olarak yapılandırıldığını ifade eder (Lefebvre, 1991b, s.404). Bu doğrultuda, kültür turizm faaliyetleri arasında yer alan yürüyüş rotalarının oluşturulması, tüm farklılıkları ve çatışmalarıyla gündelik hayatın geçtiği kent mekânının yürüyerek keşfedilmesi, duyular ve bedenin sınırlılıkları çerçevesinde deneyimlenmesi ve tarihsel-toplumsal-mekânsal boyutlarıla kente ilişkin bütüncül bilgi edinilmesine olanak sağlar.

Bu nedenle, Dünya Turizm Organizasyonu ve Birleşmiş Milletler'e göre konvansiyonel olarak “kısa süreliden kalıcı olana geniş bir yelpazedeki hareketlilik sürekliliğinin bir parçası" olarak tanımlanan turizm (Recommendations on tourism statistics, 1994, s.3); insanların, nesnelerin, bilginin, anaparanın dünya üzerindeki hareketleri gibi daha geniş ölçekli hareketliliklerin bir parçası, ayrıca günlük ulaşım, kamusal mekândaki hareketler ve gündelik hayatın içindeki maddi şeylerin seyahati gibi daha yerel süreçleri ve çağdaş hareketlilikleri de kapsar (Urry, 2007). Turizmin ve turistin tanımları değiştikçe, turizm ve turistik davranış da gündelik hayatın ayrılmaz bir parçası olarak görülmeye başlanır (Maitland, 2010, s.178). Geleneksel ya da tarihi kent merkezine yakın bazı mahalleler, kendine özgü kentli grupları için yeni deneyimler yaratabilir; bu fırsatların tüketimi ve kültürel farklılıkların birleşimi ile gündelik hayatı deneyimleme firsatı sunar (Maitland, 2010, s. 179). Kenti farklı amaç ve kapsamda deneyimleyen grupların --örneğin kentin, işadamları, akademisyenler, sanatçılar vb. günlük ziyaretçilerin, keyfi seyahat eden turistlerin hareketleri ve talepleri, kentin olağan sakinlerininkinden ayrılamaz (Hannam, 2009, s.101-104). 


\section{İzmir Kemeraltı Üzerine Güncel Çalışmalar}

Turizmde kültürel değerlere yapılan yönetsel vurgulara koşut olarak kent kültürünün aktarıldığı ya da deneyimlendiği farklı uygulamaların da son yıllarda ivme kazandığı söylenebilir. Kemeraltı özelinde bu uygulamalar, olabildiğince çok aktörlü süreçlerle ve bu süreçleri besleyen akademik çalışmalarla gerçekleşmiş olmasına karşın; yazındaki çalışmaların büyük çoğunluğunun epistemolojik yapısının çok disiplinli çalışmalardan ortaya çıkmadığı söylenebilir. Örneğin, Kemeraltı üzerine yapılmış lisansüstü çalışmaların, şehir ve bölge planlama, kentsel tasarım, mimarlık, mimari restorasyon, kentsel dönüşüm, tarih, sosyoloji ya da işletme disiplinlerine ait oldukları görülür. Bunlar arasından konuyu şehir ve bölge ile kentsel tasarım ölçeklerinde ele alan çalışmalardan bazıları şunlardır: İzmir'in tarihi ve geleneksel merkezi olan Kemeraltı'ndaki reklam tabela ve levhaları gibi bildirişim elemanlarını tasarlanması ve düzenlenmesine yönelik bir yönetmelik denemesi sunan çalışma (Geçer, 1999); kent kimliğini kentsel tasarım ölçeğinde ele alan ve Kemeraltı Kentsel Sit Alanı Tasarım Rehberi'ni (2001) bir planlama aracı denemesi olarak sunan çalışma (Aydoğan, 2001); Tarihsel nitelikli alanlara ilişkin kentsel tasarım müdahalelerinde, resmi söyleme alternatif tarihyazım yöntemlerinden mekânın mikro tarihine vurgu yapan, Kemeraltı Anafartalar Caddesi'nde kentsel kimlik, aidiyet ve kimlik ilişkilerine ilişkin gerçekleştirilen bir sözlü tarih çalışmasını ortaya koyan ve toplumsal bellek-sözlü tarih anlatılarını bütünlüklü olarak ele alacak kolektif bellek ürünü bir kentsel tasarıma bir altlık oluşturması çerçevesinde değerlendiren çalışma (Karpat, 2009); Kemeraltı'nda yeniden canlandırmaya yönelik yapılan uygulamaların incelendiği ve değerlendirildiği çalışma (Zeybek Çetin, 2012); kentsel tasarım kontrol mekanizmasında kent kimliğinin korunması, geri kazanımı, sürdürülmesinde ve yeni gelişme alanlarının planlanmasında kılavuz niteliği olan kentsel tasarım rehberlerinin Kemeraltı Kent Merkezi Canlandırma Projesi örneği ile incelendiği çalışma (Şala, 2013); tarihi kent merkezlerindeki kentsel koruma ve dönüşüm boyutlarını, İzmir Büyükşehir Belediyesi'nin İzmir'deki Kemeraltı bölgesi için geliştirdiği büyük ölçekli kentsel dönüşüm projeleri üzerinde inceleyen çalışma (Yakıcı, 2018). Araştırma konusunda olası gelecek çalışmalara önemli kaynaklar oluşturacağı düşünülen bu ve benzeri çalışmaların, çoğunlukla Kemeraltı'nın kentsel tasarım ve mimari koruma boyutlarını irdelediği; kentsel tasarım sürecine kılavuzluk etmek üzere rehberler önerdikleri ya da bunları irdeledikleri; mimarlık, sanat, zanaat, moda, tekstil vb. farklı disiplinlerin şemsiye kavramı ve edimi olan 'tasarımı' yalnızca kentsel ölçekte ve yüksek lisans düzeyinde ele aldığı ifade edilebilir².

Kemeraltı üzerine kültür-turizm-tasarım sacayağında yer alan mevcut çalışmaların ve güncel uygulamaların bütüncül bir panorama ile ortaya konması, çok-disiplinli bir bakışla ele alınacak olası çalışmalara altlık oluşturmak açısından önemlidir. Basılı ya da dijital olarak paylaşılan bu çalışmaların, İzmir İl Kültür ve Turizm Müdürlüğü, İzmir Büyükşehir Belediyesi, İzmir Konak Belediyesi, İzmir Kalkınma Ajansı, İzmir Ticaret Odası, Ege İşadamları Derneği (EGİAD), İzmir Fransız Kültür Merkezi gibi farklı kurum, kuruluş ve organizasyonlarca gerçekleştirildiği görülmektedir. İzmir İl Kültür ve Turizm Müdürlüğü’nün yayınlamakta olduğu İzmir Kültür ve Turizm Dergisi ile İzmir Turizm Envanteri konuyla ilişkili temel başvuru kaynaklarındandır (İzmir İl Kültür ve Turizm Müdürlüğü, 2000). İzmir Turizm Sempozyumu’nda kentin kültür turizmi ve turizm potansiyeli ile ilgili görüş ve öneriler paylaşılmıştır (T.C. İzmir Valiliği İl Kültür ve Turizm Müdürlüğü, 2006).

İzmir Büyükşehir Belediyesi'nin İzmir Kültür Çalış̧tayı (2009) kapsamında gerçekleştirdiği 'Kültürel Miras Atölyesi' sonucunda, kentin sahip olduğu niteliklerin turizm için kentlinin 'kültürel değer üretimi' ve 'ekonomik değer üretimi' için fırsat oluşturduğunun altı çizilmiş; kültürel değer üretiminde öncelikli alanlar belirlenmiştir. Bu çalıştayda Kemeraltı, sahip olduğu arkeolojik alanlar ve değer taşıyan noktaları, sivil mimari örnekleri ve anıtsal yapıları, müzeleri, kentlinin kültürel buluşma noktaları, diğer maddi kültürel mirasları ve somut olmayan kültürel mirasları ile kent merkezinin kültürel mirasının odağı olarak öne çıkmaktadır (İzmir Büyükşehir Belediyesi, 2009). Yanı sıra belediyenin Kültür Yayınları arasında yer alan Kent Kitaplığı Serisi ve İzmir Kent Kültürü Dergisi konuyu farklı sayılarında ele almıştır. Belediyenin de içinde olduğu kamu-özel sektör ortaklığıyla 2012 yılında kurulan TARKEM (Tarihi Kemeraltı İnşaat Yatırım A.Ş.) ‘Tarihi Kemeraltı’nın Yeniden Keşfi’ sloganıyla Kemeraltı ve Çevresi Kentsel Yenileme Alanı içerisinde farklı kültürel projeler üretmektedir (TARKEM, t.y.). İzmir Büyükşehir

2 Çalışmanın odağını oluşturan kentsel-kültürel turizm ve tasarım kültürünün haritalanması konuları, kentsel tasarım disiplininden beslenen kent kültürü, kentsel kimlik, kentli kimliği gibi kavramlar ile de desteklenebilir. Bu çalıșmanın odağındaki konuların, bu kavramlarla birlikte ele alınacağı bir ilişki üzerine yapılacak değerlendirme, ileride yapılacak olası çalışmalara bırakılmıştır. 
Belediyesi bünyesindeki İzmir Tarih Proje Merkezi'nde 2013 yılından beri İzmir'in tarih kent merkezi olarak bilinen Kemeraltı ve çevresinde projeler yürütmekte, atölye ve sergiler düzenlemekte ve bu çalışmalarını İzmir Tarih Tasarım Stratejisi Raporu gibi yayınlarla desteklemektedir (Tekeli, 2017; İzmir Büyükşehir Belediyesi İzmir Tarih Proje Merkezi, t.y.). Kemeraltı vez çevresi, İzmir Büyükşehir Belediyesi bünyesinde 2013 yılında kurulan İzmir Akdeniz Akademisi'nin 2016 yılından bu yana her yıl düzenlediği, İzmir kamusal alanlarında tasarım odaklı güncel mesleki ve kuramsal çalışmaları, sergi, atölye, panel ve söyleşi vb. farklı formatlarda etkinlikler dizisiyle harmanlayan İyi Tasarım/Good Design İzmir etkinliklerinde de ele alınmıştır (İzmir Akdeniz Akademisi, 2019). Bu çalışmalardan bazıları, İzmir Kültür Çalıştayı (2009), İzmir Tasarım Forumu (2011), Kemeraltı'ndan Kültürparka'a Tasarım Rotası Gezisi (2016), Basmane Tasarım Projesi Sergisi (2017) ve İzmir'de Bir Tasarım Rotası: Kemeraltı-Basmane'yi Haritalamak (2018) başlıklı panel olarak sıralanabilir (İzmir Akdeniz Akademisi, 2019).

İzmir Konak Belediyesi sınırları içinde yer alan Kemeraltı'nı da kapsayan çalışmalar, İzmir'i İyileştirmek: Kent Yenileme Çalışmaları 2005-2009 başlıklı bir kitapta yayınlamıştır (İzmir Konak Belediyesi, 2009). Konak Belediyesi, Kemeraltı'nın tarihi ve kültürel değerlerini 2009'dan günümüze yayınlanmakta olan KNK Dergisi'nde (t.y.) de kentliye tanıtmaya devam etmektedir. İzmir Kalkınma Ajansı ve Ege Derneği'nin kültür turizminin bir tema olmaktan çıkıp başlı başına bir sektör halinde gelişebilmesi hedefiyle 2011 yılında akademisyenler, yazarlar, sanatçılar, araştırmacılar, kamu ve meslek örgütlerinden paydaşlarla oluşturduğu “İzmir Kültür Turizmi Sektör Araştırması Analiz Raporu”, İzmir'in kültür turizmi açısından olanaklarının ve açmazlarının irdelenmesi bakımından konuya ilişkin daha kapsamlı ve güncel bir kaynak niteliğindedir (Ege Derneği, 2011). Kemeraltı'nın değerleriyle ilgili kentlide farkındalık yaratmayı hedefleyen bu çalışmaların yanında İzmir'deki eğitim kurumları da çalışmalar ve yayınlar yapmıştır. Bu çalışmaların öncüllerinden DEÜ Mimarlık Fakültesi Döner Sermayesi kapsamında tamamlanan 'Kemeraltı Koruma Amaçlı İmar Planı (2002)' ile İzmir'in tarihi kent merkezinin kentsel tasarım ölçeğinde korumasına ilişkin proje geliştirilmiştir (Ecemiş Kılıç ve Aydoğan, 2006). İzmir kent yaşamını konu alan popüler yayınlarda da Kemeraltı her zaman güncelliğini korumaktadır ${ }^{3}$

Mevcut yazında, kenti genel hatlarıyla tanıtırken Kemeraltı hakkında da bilgi veren turizm rehberlerinden bazıları T.C. Kültür ve Turizm Bakanlığı İzmir İl Kültür ve Turizm Müdürlüğü’nün (Kent rehberi, t.y.), İzmir Büyükşehir Belediyesi'nin (İzmir'de bir gün - Turizm rehberi, t.y.), (Turistik gezi rotası hazırlıyoruz, t.y.), İzmir Dergisi'nin (Gezi rehberi, t.y.), İzmir Ticaret Odası'nın (İzmir rehberi, t.y.), İzmir Guide Dergisi'nin (Kemeraltı rotası, t.y.) olarak sıralanabilir. Turizm rehberleri yanı sıra, İzmir'in kültür turizmini farklı açılardan destekleyen rehber niteliğinde kitaplardan başlıcaları şunlardır: Guide to İzmir rehberi (Aksoy, 1992), Tarihten Günümüze İzmir Mutfağı (Atilla, 2001), Kemeraltı'nın İzmir’i: Tarih Kültür ve Gezi Rehberi (Taşkıran, 2008), Adım Adım İzmir ve Çevresi - İzmir Guide (ürük, 2009), Ayaküstü İzmir Sokak ve Fırın Lezzetleri (Yentürk, 2018).

Turizm ve mimarlık yazınındaki tartışmalar çoğunlukla kültürel miras ve koruma üzerinde yoğunlaşsa da; mimarlıkkültür-turizm ilişkisini daha genel perspektiften ele alan çalışmalar (İncedayı, 2005) ve özellikle son on yıldır İzmir'de farklı sektörlerin odağı haline gelen Kemeraltı'nı daha erken bir vizyonla mimarlık gündemine taşıyan çalışmalar mevcuttur (Kayın, 2002). Mimarlar Odası İzmir Şubesi'nin süreli yayını Ege Mimarlık Dergisi'ndeki muhtelif makalelerin yanı sıra, İzmir Büyükşehir Belediyesi ve Mimarlar Odası İzmir Şubesi ortak çalışması olan İzmir Kent Merkezi Mimarlık Haritası (2004) ve İzmir Mimarlık Rehberi (2005) yapılı çevrenin haritalandığı önemli çalışmalardır. Ayrıca, İzmir kültür turizmi kapsamında kamu/özel sektör girişimi gezilerin ve rehber kitapların da son yıllarda basılı ve dijital ortamda artış gösterdiği not edilmelidir.

Kent-kültür-turizm sacayağındaki çalışmalar, farklı tema-içerik-sürelerde geziler ve bu gezilere eşlik eden rehber kitaplar aracılığıyla kentliyle buluşur. İzmir Büyükşehir Belediyesi'nin güncel projelerinden biri, Kent Rotası Projesi adıyla “kente gelen ziyaretçileri Alsancak Limanı'nda karşılayıp Kemeraltı Çarşısı'na ulaştırma ve ziyaretçilerin kent merkezinde geçirecekleri süreyi artırma amacıyla hazırlanan" turistik gezi rotasıdır (İzmir'de bir gün - Turizm rehberi, t.y.). Bu çalışmalardan bir diğeri de --tasarım, tasarım kültürü, tasarım tarihi gibi konuların İzmir kenti özelinde karşılıklarının aranması ve kentle/kentliyle buluşturulması hedefiyle-- 4T (Tasarım ve Tasarım Tarihi Topluluğu) Derneğ

\footnotetext{
3 Bu dergilerin başında İzmir Life Dergisi yer alır.
} 
Kültür ve Gezi Komisyonu'nun gerçekleştirdiği kent içi geziler için kültür-tasarım rotaları haritası oluşturma denemesidir. Bu deneme kapsamında, kent kültürü-tarihi ve tasarım kültürü-tarihi açısından önemli verileri barındıran İzmir Kemeraltı'nın kültürel değerleri tasarım odağında haritalanmıştır (Hakkında, t.y.).

\section{‘Kültürel Haritalama’nın Haritalanması}

İnanç sistemlerini, eğitimin yönünü, medyayı, turizmi, toplumsal gelişimi, planlamayı ve yaratıcı endüstrileri şekillendiren kültür ve deneyim, insanların yer algılarını da etkilemektedir. Yüzyıllardır çeşitli amaçlar için kullanılagelen haritalama (mapping), doğal ve kültürel peyzajların temsilinde vazgeçilmez bir araçtır. Haritalar da yaşadığımız yeri makro ve mikro ölçeklerde çeşitli perspektifler, ölçekler, duyular ve değerler ile görmemizi ve anlamamızı sağlar. Kişisel ve toplumsal ölçekte yer algılarını etkileyen faktörleri anlamada kültürel haritalama, kelime anlamıyla ya da metaforik anlamıyla, toplumsal, kültürel, ekonomik vb. farkı topoğrafyaları, coğrafi haritacılığın ötesinde alternatif tekniklerle kaydeder. Uzun yıllardır mimarlık, kentsel tasarım, coğrafya, sosyoloji, kültür politikaları ve planlama, medya çalışmaları gibi kültürel ve sanatsal çalışmalarda mekân ve yeri önceleyen bakışı yansıtan farklı alanlarda, farklı amaç ve kapsamlarda kullanılan (Stewart, 2007), farklı teknik ve etkinlikleri kapsayan kültürel haritalama, somut ve somut olmayan kültürel varlıkların belgelenmesi, korunması ve sürdürülmesinde önemli bir araç ve tekniktir (Cultural mapping, 2019; Longley ve Duxbury, 2016; Evans ve Foord, 2008; Stewart, 2007). Kültürel çeşitliliğin korunması ve sürdürülmesi için bir topluma ve yere özgü kültürel unsurları oluşturan galeriler, el sanatları üretim pratikleri, yerel endüstriler ve etkinlikler gibi somut varlıkların yanı sıra anılar, kişisel tarihler ve yaklaşımlar gibi somut olmayan varlıkların araştırılması sonrasında, kaydedilmesini kapsar (Stewart, 2007; Cultural mapping, 2019). Sutherland ve Young'dan (1995) aktarıldığ üzere, "kültürel haritalamanın en temel amacı, toplulukların ekonomik, toplumsal ve bölgesel kalkınma için kültürel çeşitliliği tanımalarına, kutlamalarına ve desteklemelerine yardımcı olmaktır” (Cultural mapping, 2019). Kültürel haritalama, farklı bölge ve toplulukların sosyal ve ekonomik gelişmesinde için bir araç olarak; şehirlerin ve bölgelerin gelişiminde yerel kültürel kaynakların stratejik kullanımını içeren kültürel planlamanın temel aşaması olarak kullanılmaktadır (Evans, 2001; Eräranta, Leino, Seppälä, Vina ve Timonen, 2016). Kültürel haritalama süreçlerinin tipik sonuç ürünü olan gerçek haritalar, sanatçıların el üretimlerinden inretaktif çevrimiçi multi-medya haritalara farklılaşan çeşitli biçimlerde ortaya çıkmaktadır (Stewart, 2007). Son yıllarda daha da kabul gören haritalama sırasında toplanan veriler, coğrafi haritalar, uydu görüntüleri, hava fotoğrafları, grafikler, diyagramlar, istatistiksel veritabanları gibi çeşitli formatlarla gösterilebilir. Coğrafi Bilgi Sistemleri (GIS) yazılımı gibi yeni bilgi ve iletişim teknolojilerinin gelişimi ile web tabanlı haritaların artan kullanımı olanaklı hale gelmiştir (Evans ve Foord, 2008, s.78; Stewart, 2007).

Kapsamlı bir şekilde görselleştirilerek belgelenen kültürel veriler insanların, yerlerin yanı sıra somut ve somut olmayan üretimlerin analizlerine temellenen ulusal, bölgesel ve yerel stratejilerin geliştirilmesi önemli bir kaynak oluşturur (Cultural mapping, 2019). Kültürel haritalama, farklı amaçlarla kapsamlarda ve kullanıcılara 'topluluğun güçlendirilmesi/ eşleştirilmesi', 'kültür politikası', 'kültürel haritalama ve idari yönetişim', 'kültürel haritalamaya sanatsal yaklaşımlar' ve 'akademik sorgulama' olarak sıralanabilecek birbiriyle ilişkili farklı güzergahlarda gerçekleştirilebilir (Duxbury, Garrett-Petts ve MacLennan, 2015). Haritaların kültürel yapısından haritaların kültürel araştırmanın aracı olarak kullanımına çeşitli konuları içerir (Longley ve Duxbury, 2016). Bu çalışma, Kemeraltı kültürünün akademik bir araştırma olarak haritalanması ve tasarım kültürü haritasının oluşturulması pratiği üzerinedir.

Melez bilgi türlerini bir arada tutan bir araştırma şekli olarak kültürel haritalama, sanatsal çalışmalardan topluluk yönetimine pek çok araştırma alanında kullanılmaktadır. İlgili yazında, somut olmayan kültürel değerleri haritalama konusunda farklı bakış açıları sunan farklı kapsam ve içerikte çalışmalar mevcuttur: 'Gelişim planı aracı olarak' kültürel haritalama (Freitas, 2016); “kentsel mekânların duyusal ve duygusal boyutlarına ve çoğunlukla göz ardı edilenlere odaklanarak Durumcular'ın deneysel dérive (kentte amaçsızca savrulma) yöntemiyle birleştiren haritalama" (Radović, 2016); "yerin fiziksel, toplumsal ve tarihsel boyutlarına orada yaşayanların verdiği anlamları yaratıcı bir şekilde kurgulayan, yorumlayan ve bu yolla yerin kimliğini yeniden inşa eden haritalama” (Eräranta, Leino, Seppälä, Vina ve Timonen, 2016; Longley ve Duxbury, 2016).

Kültürü oluşturan unsurlarla teması düşünüldüğünde, tasarımın ve tasarımda belli sürekliliklere ve asal niteliklere temellenen tasarım kültürünün haritalanması da son yıllarda önemsenmeye ve gündeme gelmeye başlamıştır. İzmir için de farklı tema, kapsam ve içerikte rotalar, kültür turizminin anıtlar, müzeler ve tema parkları gibi çekim noktaları yanı sıra tarihikültürel ve sanatsal etkinlikler şeklinde sınıflandırılabilecek 
çekicilik unsurları arasında önemli yere sahiptir. Çeşme Uluslararası Turizm Semineri'nde (2013) de vurgulandığı gibi, "kültür rotalarının oluşturulması, kültürel miras hakkında farkındalığı artıran kültürel etkinliklere yaygın katılımı teşvik eder; kültürel ve toplumsal ilkeler üzerine kurulan kültürel rotalar, yenilik, yaratıcılık, küçük işletme yaratma kaynakları yanı sıra kültür turizmi ürünleri ve hizmetlerinin geliştirilmesine kaynak oluşturur. Bu açılardan kültür turizmi, uluslararası, ulusal ve yerel düzeyde turizmin gelişimi öncelikleri arasında yer alır" (Tourism at world heritage sites, 2013, s.24). Bu kapsamda, kent içi gezilere bir altlık oluşturmak üzere, 4T Derneği Kültür ve Gezi Komisyonu tarafından İzmir Kemeraltı'nın kültürel değerlerini kültürtasarım odağında ele alan bir tasarım kültürü haritalama pratiği gerçekleştirilmiştir (Hakkında, t.y.). Bu haritalamadan üretilen gezi rotalarından biri, derneğin 2016 ve 2017 yıllarında düzenlediği sempozyum programlarında yer almıştır (Hakkında, t.y.) ${ }^{4}$. Şekil 1'de Kemeraltı'nın tasarım kültürünün haritalanması sürecinde üretilen taslak haritalar ile gerçekleştirilen sempozyum turu ve tasarım rotası görülmektedir. Bu pratiği daha detaylı bir biçimde irdelemek, Kemeraltı'nın İzmir kenti kültür turizminin geliştirilerek sürdürülmesi açısından önemlidir.

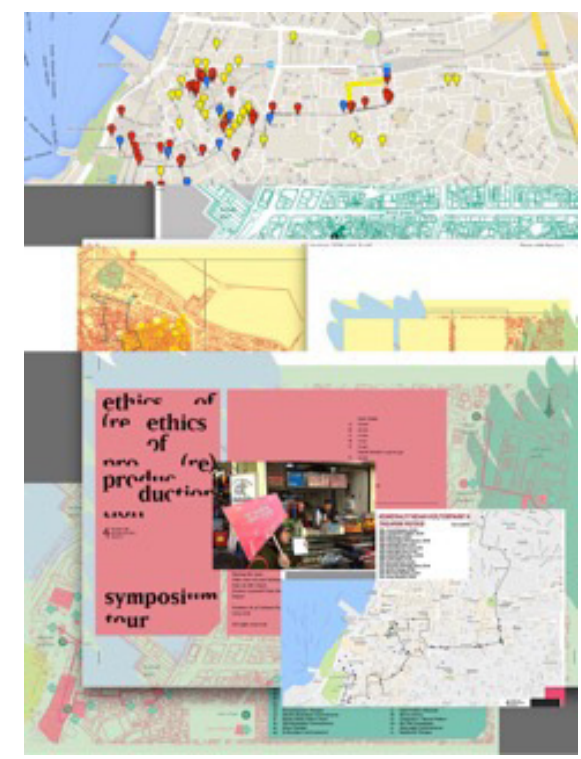

Şekil 1. Sempozyum turu ve tasarım rotasından fragmanlar, İzmir, 2018 (Kişisel arşiv).

4 Ayrıca aynı çalışmadan yola çıkılarak, İzmir İyi Tasarım Günleri_I kapsamında G. Savaşır, D. Himam Er, B. Pasin tarafından 19 Kasım 2016 günü kentlilerin katılımına açık “Kemeraltı’ndan Kültürpark’a Tasarım Rotası” başlıklı bir gezi de gerçekleştirilmiştir (Kemeraltı'ndan Kültürpark'a tasarım rotası, t.y.).

\section{Kemeraltı Kültürünün Haritalanması}

Son yıllarda yerel, ulusal ve uluslarası düzeylerde turizmin oluşmasında kültür turizmi, kültürel değerlerin sürdürülebilirliği ve korunması konuları ile ilintili kültürel rotaların sayısı giderek artmaktadır. Avrupa Kültür Sözleşmesi'ni (1954) 1957 yılında imzalayan Türkiye'de, turizminde önemli role sahip tarihi ve kültürel değerleri öne çıkarmak üzere geliştirilen Likya Rotası, Troya Rotası, Hitit Rotası, Gurme Rotası vb. kırsal kültür-turizm rotaları (Görmüş, 2018; Tüm rotalar, 2017) yanı sıra yere ait özgün somut ve somut olmayan değerlerin, deneyimlerin ve gündelik hayat pratiklerinin izlerini süren ve bir araya getiren kentsel kültür-turizm rotalarının önemi de gittikçe artmaktadır. İzmir Büyükşehir Belediyesi'nin Yarımada İzmir Gezi Rotaları, İzmir ili özelinde bu kapsamda hazırlanmış en kapsamlı ve güncel örnektir. Efes-Mimas Yolu, yarımadadaki tarihin izini süren rotalara verilen ortak isimdir; yürüyüş ve bisiklet yolları ile geçilebilen parkurlar yanı sıra zeytin ve bağ temalı rotaları kapsar. "Toplam 709 km uzunluğunda 49 parkurdan oluşan” yürüyüş yolundaki rotalar, "plajlar, orman kampları, günübirlik turizm bölgeleri, kazı alanları ve ören yerleri, müzeler, zeytinlikler ve işlikler, bağlar, köy pansiyonları, yöresel lezzetlerle tatlanan mekânlar, pazaryerleri, şenlik ve festivaller ile kesişir" (Yarımada İzmir, t.y.). Burada bahsi geçen ve İzmir kent merkezinin dışında kalan zeytin rotası, İzmir özelinde Avrupa Konseyi Kültür Rotaları üyesi olarak kabul edilen tek kültür rotasıdır (Cultural Routes - Routes4U Project, t.y.).

Kent merkezindeki çekim noktalarından biri olarak, kısıtlı bir kapsamla İzmir turistik rehberlerinde ve rotalarında yer alan Kemeraltı, dijital ortamda açık erişimli olarak hazırlanmış İzmir Guide web sayfasındaki rotalardan biridir. Aynı sayfadaki diğer rotalar, yürüyerek camiler rotası, havralar rotası, kiliseler rotası, müzeler rotası, alış-veriş rotasıdır. İsminin vadettiğinin aksine yalnızca İzmir'den birkaç tarihi kültürel yapıуı bir araya getiren 3 ve 6 saatlik rotalar, bir günlük ya da bir gecelik rotalara da aynı siteden erişilebilse de (Rotalar, t.y.); İzmir kent merkezi ve Kemeraltı'nın çok katmanlı yapısını yansıtmakta zayıf kalmaktadır. Örneğin aynı rotalara eşlik etmek üzere hazırlanan harita, Kemeraltı bölgesini yapı ve yapı adaları düzeyinde göstermeyerek, başlıca cadde ve sokakların gösterildiği soyutlukta bir grafik dille hazırlanmış bir harita üzerinde, 3 adet idari bina, 6 adet cami, 4 adet kültür-sanat [yapısı], 7 adet han, 4 adet görülecek yerler başılıları ile verilmiştir (Rotalar, t.y.). 
Bu çalışmada ele alınan kültürel haritalama pratiğinin kaynakları arasında yer alan İzmir Kent Merkezi Mimarlık Haritası (2004) Alsancak, Kültürpark Fuar Alanı, Pasaport, Çankaya, Gümrük, Hisarönü, Kemeraltı, Mezarlıkbaşı, Basmane, Konak, Varyant ve Karataş semtlerini kapsar ve bu semtler arasından Kemeraltı'na odaklanmış bir haritada yeniden gösterir. İzmir kent tarihçesi başlıklı bir metin haritaya eşlik eder. Haritada 94 mimari öğe gösterilmiş; mimarları, yapım tarihleri, adresleri ve yapılara ait küçük bir görsel haritanın altına eklenmiştir. Metro duraklarının, sokak ve cadde isimlerinin belirtildiği konvansiyonel turistik haritalardan farklı olarak, bu mimarlık haritası kentsel dokunun doluluk-boşluk detayını yapı ölçeğinde gösterir ve mimari yapıları vurgulayacak şekilde tasarlanmıştır. Aynı çalışma kapsamında 2005 yılında yayınlanan İzmir Mimarlık Rehberi İzmir kent tarihi, İzmir’de mimarlık başlıklı iki giriş yazısının ardından, İzmir kent merkezinde yer alan 159 yapı ya da yapı grubu bölgelere göre gruplandırılarak haritalamış; her bir öğeyi mimarı, yapım tarihi, adresi ve öğeye ait fotoğraflar, plan ve kesit çizimlerinin de verildiği birer sayfalık tanıtım metinleriyle ele almıştır. Rehberdeki gruplandırmaya ve çalışmanın sürecine ilişkin bilgilerin açıklandığı bir giriş yazısının ya da haritalarda lejand bulunmaması, rehberin anlaşılabilirliğini kısıtlamaktadır (Güner, 2005). Benzer kapsamda hazırlanan bir diğer çalışma da TÜBA / TÜKSEK Adana Kentsel Kültür Varlıkları Envanter Çalışması ile elde edilen verilerden yola çıkılarak 2006 yılında hazırlanan Adana Mimarlık Rehberi 1900-2005'dir. Adana'nın kentsel gelişiminin ve karakteristik mahallelerinin irdelendiği bir yazı ile başlar; fonksiyonlarına göre gruplandırılmış tek ya da grup yapılar hakkında saptamalar yapılmış ve ardından bu yapıların adı, yapım yılı, mimarı ve adresinden oluşan künyesi, tanıtım metni ve görselleri bir ya da nadiren iki sayfada verilmiştir (Saban, Karaman, Erman ve Durukan, 2006). Türkiye bağlamında gerçekleştirilmiş nadir mimarlık haritalama çalışmalarının ürünleri olmaları nedeniyle çok değerli olan her iki rehber de, metin ağırlıklı oluşları, kentte yürürken kullanımlarının kolay olmayışı ve kitapların sonunda verilen anahtar haritaların grafik tasarımlarının kullanıcıdostu olmayışı ile eleştirilebilir.

Farklı metropol kentleri için geliştirilen mimarlık rehberleri de çalışmanın başlangıç noktasında incelenmiştir. Örneğin Stuttgart mimarlık rehberi de, Türkiye örneklerindeki gibi, 8 bölgesel gruplama altında yapılara ait bilgileri kısa tanıtım metinleri ve görsellerle aktarır (Franke-Höltzermann,
2006). Berlin için hazırlanan mimarlık rehberinde, haritalanan yapılar kentte baskın olarak hissedilen 9 mimari döneme göre gruplandırılarak tanıtılmış ve 45, 50, 60, 75, 90 ve 105 dakikalık 10 farklı rota önerilmiş ve bu rotalara odaklı haritalar üzerinde gösterilmiştir (Haubrich, Hoffmann ve Meuser, 2006). 1981 yılında kurulan Architectural Tours adlı oluşumun bir ürünü olan Londra mimarlık rehberinde de, gezilmek istenecek 7 alan ve mahalledeki yapılar coğrafi olarak gruplandırılmış ve listelenmiş, yapılara ait tanıtım metinleri ilgili görseller o yapılara ilişkin küçük notlar/ ipuçları eklenerek verilmiştir. Rehberin başında yer alan 'kimler için' ve 'bu rehber nasıl kullanılır' başlıklı notlar, kısa ve kullanışlıdır (Allinson, 2009).

Ulusal ve uluslararası yayınlar arasında ülke ve şehir özelinde olarak hazırlanmış konvansiyonel kapsam, içerik ve gösterim biçimlerine sahip çeşitli ve çok sayıda turistik gezi rehberleri mevcuttur. Gelişen teknoloji ile entegre olmuş dijital haritalar, kültür rotaları, mimarlık rehberlerinin özellikle son 10 yılda geliştirilmesi ve aktif kullanımı da basılı haritaları turizm faaliyetlerindeki konumunu değiştirmeye başlamıştır. Öte yandan, basılı ya da dijital ortamda sunulan haritalar, hala konvansiyonel haritalama pratiklerine temellenmektedir. Bu haritalama pratiklerine ve rehberlere alternatif oluşturabilecek yeni nesil kent rehberlerinden biri ise Beyrut kent rehberidir (Ernsten, 2014). 21. yüzyılın kent kaşifleri için el rehberi olmayı hedefleyen çalışma, çok katmanlı Beyrut kentine ilişkin öznel keşifleri odağına alan ilk izlenim, resmi kent, duygusal kent, icat edilen kent gibi bölümlerden oluşur; kenti farklı boyutlarıyla kolajvari bir kurguda metinler, bilişsel haritalar, illüstrasyonlar, kentten çarpıcı detay fotoğraflar, karikatürize çizimler, Beyrut’ta ucuz bir günlük tur, tarihi kent merkezi turu, kentsel mitler, kentsel sokaklarda kaybolmaya davet eden yürüyüş haritaları, gündelik hayat ve kent kültürüne ait nesne ve mekanların çarpıcı görselleri, beklenmedik tarih dersi metni vb. ile keşfe sunar (Ernsten, 2014). Rehber, tüm bu katmanl, renkli ve kenti keşfe davet eden içerik ve grafik diliyle önemli bir kaynaktır.

Bu makalenin konusunu oluşturan Kemeraltı'nın tasarım kültürünü odağına alan kültürel haritalama pratiği, Temmuz 2015-Mart 2018 tarihleri arasında gerçekleştirilmiştir. Bu haritalama, Kemeraltı'na ilişkin mevcut araştırma ve çalışmaların kavramsal olarak irdelenmesi; yazılı, sözlü, görsel ve deneyimsel verilerin toplanması, analizlerinin yapılması; dökümün haritaya işlenmesi aşamalarını içerir. Arşiv 
araştırmaları, kişisel gözlemler ve sözlü tarih çalışmalarıyla desteklenen alan çalışması ile yüzlerce öğenin mimarı/ tasarımcısı/sahibi, yapım/üretim tarihi, adresi, fotoğrafı vb. bilgileri toplanmıştır. Belgeler, gözlemler ve analizlerle bütüncül olarak toplanan bilgiler tematik gruplandırmayla haritalanmış; gruplar ve öğeler arasında kurulan ilişkiler ağı irdelenmiştir.

$\mathrm{Bu}$ haritalama pratiğinin ilk adımında, çalışma ekibi Kemeraltı'nı farklı zamanlarda ve kapsamlarda ziyaret etmiş; ardından, ekip yere ilişkin deneyimlerini ve bulgularını ortaya koymuştur. Öznel deneyimlerden oluşan bu bulgular, güncel ve tarihsel yazından, arşiv malzemelerinden elde edilen bilgilerle zenginleştirilmiştir. Kent arşivleri kadar güncel pratikler de kaynak niteliğinde ele alınmış; yerin süregiden gündelik hayatı, kentsel-ulusal-uluslararası ölçeklerdeki ilişkileri de göz önünde bulundurulmuştur. Yer hakkında olduğu kadar bir taraftan da, haritalama pratiğinin kimler tarafından, ne zaman, hangi kapsamda, hangi araç ve yöntemlerle gerçekleştirileceği irdelenerek kurgulanmıştır. Daha geniş bir ekip çalışmasının devamı niteliğindeki çalışmanın kurgusunu oluşturan ve süreci yöneten -aynı zamanda bu makalenin de yazarı olan- kişi, üretilen metinlerin editörlüğünü ve yere ilişkin fotoğrafların çekimini de üstlenmiştir. Araştırmacılardan ikisi, yerel halktan konuyla ilişkili aktörlerle deneyimleri, gelecek beklentileri ile ilgili tematik görüşmeleri yapmış; bu kişilerin anılarını ve deneyimlerini de toplamak üzere sözlü tarih çalışmaları gerçekleştirmiştir. Elde edilen veriler, tematik olarak gruplandırmış; gruplardaki her öğenin künye bilgileri tablolaştırılmıştır. Araştırmacılar tarafından derlenen farklı malzemeler kişisel olarak işlenmiş; oluşturulan bilgilerin nitel analizi 11 toplantıda ekipçe yapılmıştır. Her öğeye ait elde edilen yazılı malzeme, veriye dayalı biçimde (tanımlayıcı, tarihsel, belleğe ait vb. özelliklerini yansıtacak şekilde) gruplandırılmıştır. Gadamerci düşünce çerçevesinde, bilgilerin toplanması-işlenmesi-analiz edilmesi süreçleri, haritalama süreci boyunca gerektiği durumlarda tekrarlanmıştır.

Yapı-yapılı çevre, moda-tekstil, sanat-zanaat, üretimbellek temalarında gruplanan iki yüzü aşkın öğenin haritalandığı alan, Konak Meydanı, Milli Kütüphane ve Elhamra Sahnesi, Salepçioğlu Camii, Konak Camii, Kızlarağası Hanı, Kestanepazarı Camii, Havra Sokağı, Tarihi Agora, Dönertaş, Basmane Garı gibi farklı odak noktalarıyla anılan alt bölgelere ayrılmıştır: Hisar Camii (1596), Kestanepazarı Camii (1663), Başdurak Camii (1652), Kızlarağası Hanı (1744), İzmir Saat Kulesi (1901), Konak Yalı Camii (1748), Milli Kütüphane (1933), Yeni Şükran Oteli (1905), Kavaflar Çarşısı (1929) gibi geleneksel ve modern mimari öğenin nirengi olduğu yapılı çevre içinde, Butik Zuhal Giyim (1973), Hisar Kumaş (1960), Hasan İkbal Kumaş Mağazası (1947) ve Terzi Cemil
Yılmaz (1990’lar) gibi moda ve tekstil alanındaki üretimlerin temsilcileri; alandaki sayısız sanat ve zanaat üretimleri arasından Kızlarağası Hanı'nda yer alan ve turistik anlamda ön plana çıkan bakır, gümüş, doğal taş, deri takı ve el sanatları atölye ve ticarethaneleri ile çarşının ve kentin gündelik hayatının önemli unsurlarını oluşturan Kestanepazarı Camii çevresinde yer alan bakırcı ve fıçıcılar; Aktaş Kolonyaları (t.y.), Yudumla Şerbetçisi (1971), Köfteci Mehmet (1975), Değirmen Baharat (t.y.), Meşhur Hisarönü Şambalicisi (1939), Mennan Pastanesi (1936) ve Bizim Lokanta (t.y.) gibi Kemeraltı'nın üretim ve gündelik hayat pratiklerinin belleklerde yer alan temsilcilerinden bazılarıdır.

Künye bilgileri ile tanıtım metinleri; yanı sıra yapılı çevre, sanat-zanaat, moda-tekstil, üretim-bellek şeklinde gruplandırılan temalar üzerine değerlendirmelerinden oluşan tematik giriş yazıları hazırlanmış ve tüm metinlerin editör düzeltmeleri yapılmıştır. Araştırmacılardan ikisi haritalama pratiğinin sonuç ürünleri olan harita ve rehberin görsel dili ve malzemesinin (illüstrasyonlar, eskizler vb.) üretimi üzerine yoğunlaşmıştır. Her öğe, Kemeraltı'nda yürürken kolay bir şekilde keşfedilebilecek ve o öğenin karakteristik yönünü ortaya çıkaracak şekilde, göz hizasından ve normal açılı lens kullanılarak fotoğraflanmıştır. Fotoğraflar tematik ve ardından öğe bazında gruplandırılmış ve yaklaşık 300 öğenin haritalama çalışması sonuçlanmıştır. Şekil 2'de yapı-yapılı çevre öğelerinin bazılarının fotoğraflarından oluşturulan foto-kolaj görülmektedir. Moda-tekstil öğelerinden bazıları için Şekil 3'de; sanat-zanaat öğelerinden bazıları için Şekil 4'deki gibi foto-kolajlar oluşturulmuştur. Belleklerde Kemeraltı'nda üretim ve gündelik hayata ilişkin yer alan öğeler de fotoğraflanmış ve Şekil 5'deki gibi foto-kolajlar oluşturulmuştur. Çalışma, haritalama pratiğinin sonuç ürünleri olarak planlanan haritaların ve tematik yürüyüş rotalarının görselleştirilmesi ile tasarım rehberinin yayına hazırlanması aşamasındadır.

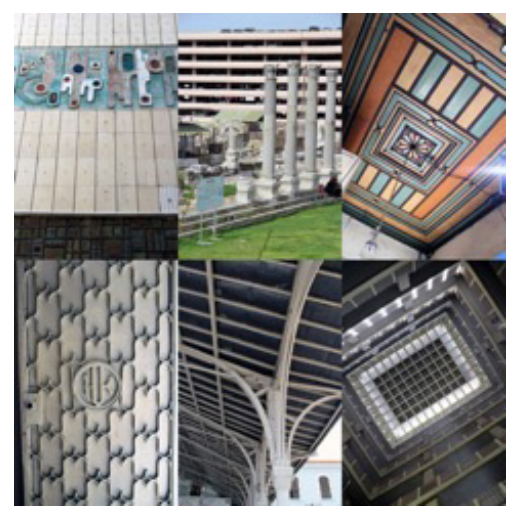

Şekil 2. Kemeraltı'ndaki yapı ve yapılı çevre öğelerinden detaylar, İzmir, 2018 (Kişisel arşiv). 


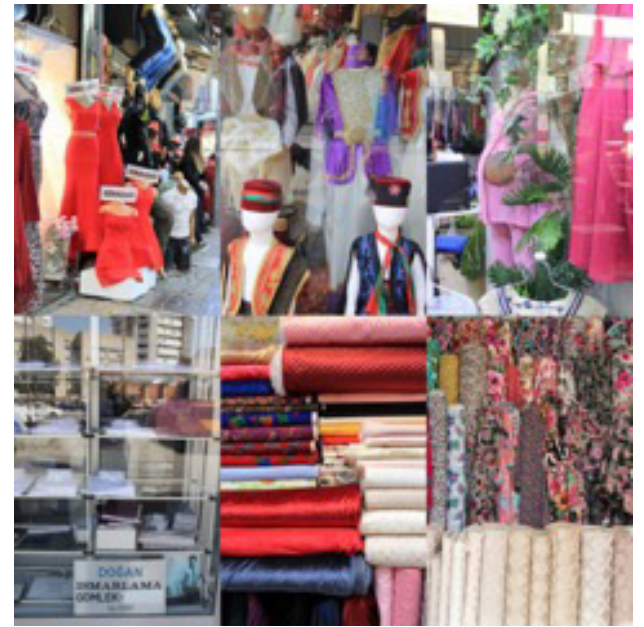

Şekil 3. Kemeraltı'ndaki moda ve tekstil alanlarındaki öğelerden detaylar, İzmir, 2018 (Kişisel arşiv).

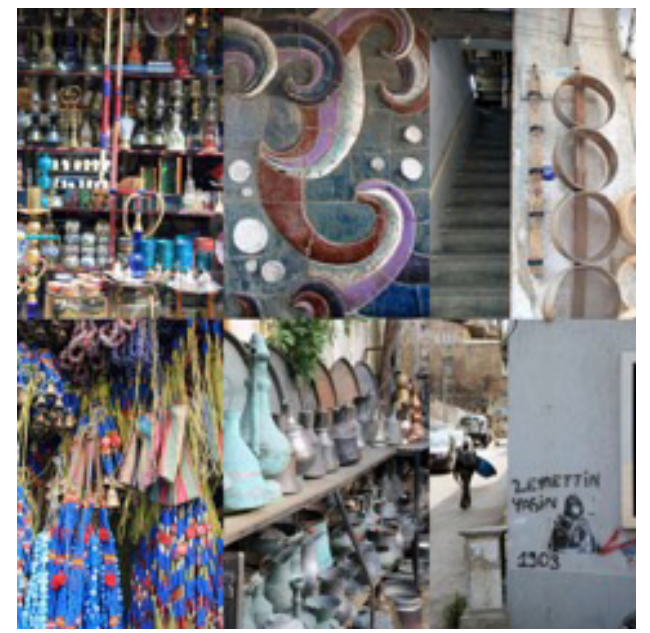

Şekil 4. Kemeraltı'ndaki sanat ve zanaat alanlarındaki öğelerden detaylar, İzmir, 2018 (Kişisel arşiv).

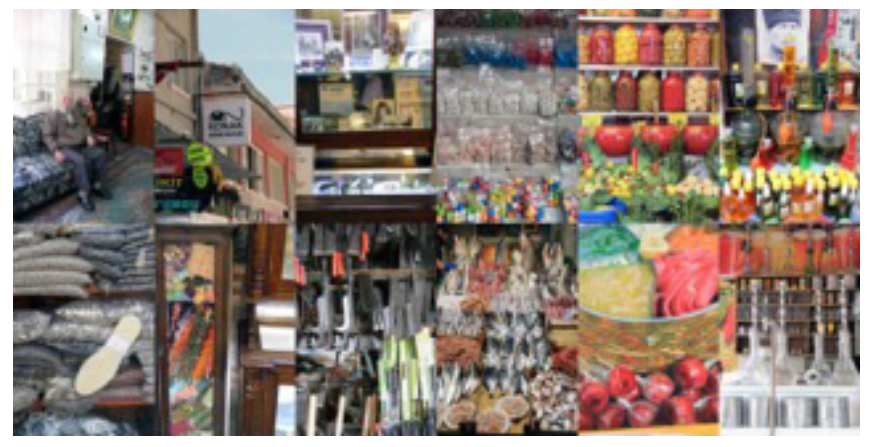

Şekil 5. Kemeraltı'nda üretim ve gündelik hayata ilişkin belleklerde yer alan öğelerden detaylar, İzmir, 2018 (Kişisel arşiv).
Kemeraltı'nın kültürel haritalanması pratiğinin ortaya koydukları irdelendiğinde Kemeraltı'nın değerleri iki altgrupta toplanabilir: Kemeraltı'ndaki üretimin, ticaretin, mal, araç ve insan hareketlerinin yüzyıllardır var olageldiği yapılı çevre, bu alanın kültürel değerlerinin somut göstergesidir. Öte yandan, Kemeraltı'nda, yapılı çevreye göre daha kısa ömürlü, akışkan ve soyut değerler olarak sayılabilecek, insanlar, insanlar-üretim pratikleri, üretim pratikleri arası ilişkiler de kültürel değerlerin toplamında somut olanlar kadar önemli role sahiptirler.

Burada haritalama (mapping), alandaki değerlerin dökümünün yapılması ve mevcut haritalar üzerine işlenmesi, tematik olarak gruplanması, parçalar ve tematik gruplar arasında yatayda, düşeyde ve çaprazlama ilişkiler kurarak rotalar oluşturulması gibi bir dizi çalışmayı da içeren şemsiye bir kavram olarak kullanılmıştır. Dolayısıyla harita, somut varlıkların yeryüzündeki konumlarını gösteren bir temsil nesnesinin ötesinde, alanın farklı yürüyüş rotalarında deneyimlenebileceği olasılıkların tümünü içeren çok katmanlı bir bilgi sistemi - ya da rota haritası- olarak düşünülmelidir. $\mathrm{Bu}$ sistemin sunduğu olasılıklar üzerinden farklı bilgiler okunabileceği gibi; farklı rotalar ve onların analog ve dijital ortamlarda temsil edildiği haritalar tasarlanabilir; farklı kapsam, içerik, süre ve katılımcılar için çeşitli geziler düzenlenebilir; bu olası gezilere eşlik etmek üzere yine farklı ortamlarda rehber kitaplar oluşturulabilir ve mobil uygulamalar tasarlanabilir.

$\mathrm{Bu}$ kültürel haritalamanın sunduğu olasılıklardan biri, birbirinden farklı kapsam ve içeriklerde zamansal/ tematik rotalara altlık sunuyor oluşudur: a) Zaman temelli rotalar, başlangıç noktalarına ve yürüme hızına göre bir saatlik, yarım günlük, bir günlük; b) Tematik rotalar, dönem mimarlığı, geleneksel yapı tipolojileri, pasajlar-kestirmeler, kent dokuları-malzemeleri, moda-tekstil, sanat-zanaat, tatkoku, ses-müzik, üretim-bellek, gündelik hayat, etnik kimlikİzmirlilik kimliği vb. çeşitlilikte olabilmektedir. Yerli/yabancı turistlere olduğu kadar kentlilere yönelik de kurgulanan bu zamansal/tematik rotalar, düzenlenecek gezilerde kentlilerin deneyimine sunulabilir.

Kemeraltı'nın çoğu zaman göz ardı edilen nesne, mekân ve üretimlerine tasarım paydasında odaklanmak; mimari, tekstil, gıda, kozmetik, vb. üretimlerinin birlikte keşfedilebileceği deneyimler sunmak; akademik ve kentli deneyimlerinin harmanlandığı çok katmanlı bir kültürel haritalama oluşturmada vazgeçilmezdir. İzmirliler için 
tanıdık olduğu kadar, her seferinde yeni deneyimler de sunan Kemeraltı için farklı kültür-tasarım rotalarını barındıran bir haritalama yapabilmek, konuya yeni çerçeveden bakabilmeyi ve alanı yeniden keşfetmeyi gerektirir.

\section{Değerlendirme ve Sonuc}

Kültür turizmi, günümüz toplumlarında kültürün ve turizmin gelişimiyle değişip dönüşmektedir. John Urry’nin (2015) işaret ettiği gibi, politik ve ekonomik değişkenlere koşut olarak toplumun ve turistik faaliyetlerin kültürel dönüşümü ile birlikte, kültür ve turizm arasındaki kesin sınırlar muğlaklaşmakta, toplumsal pratiklerin ayrılmaz parçası haline gelmektedir. Kültürel turizm araştırmalarında yeni eğilimler ve gelecek yönelimlerin altını çizen Greg Richards'ın da belirttiği gibi, kültürel turizm geliştikçe turizmin kültürel objesi değişmekte ve istisnai olan arayışı gündelik olan arayışıyla birleşmiştir (Richards'ın makalesinden aktaran, Richards, 2019, s. 598). Günümüzde kültürel turisti ve kültürel turizmin nesnesini statik kategoriler ile tanımlamak giderek zorlaşsa da (Richards, 2019, s. 598), son on yılda sosyal bilimlerde yaşanan dönüşümlere dayanan 'yeni kültürel turizm' kavramından bahsetmek olasıdır (Kjaer Mansfeldt'in tezinden aktaran, Richards, 2019, s. 598). Sanat, zanaat, moda, mimarlık, fotoğraf ve grafik gibi tasarım şemsiyesi altında birleşen disiplinlerin faaliyet alanları, toplumsal boyutlar ve dönüşüm ile birlikte düşünülmesi, kent kimliği ve kültürü içinde tasarım odaklı kültürün haritalanmasını ve turizm çalışmaları içinde yeni bir kültürel turizm alt alanı olarak yer edinmesini gündeme getirir. Öte yandan, bir turizm destinasyonunun karakterini belirleyen turistik ve çoğunlukla tarihi öğeler, o yerin 'görülmesi tavsiye edilenleri' listesini oluşturur. Bu noktada, turizm alanının geleneksel pratiklerinde otantiklik, turistik çekim noktalarını oluşturmada önemli olmakla birlikte; son yıllarda turizm alanında yapılan çalışmalarda, 'yeni kentsel turizm' kavramının tartışılmaya başladığı görülmektedir (Maitland, 2008; Maitland, 2010).

Kentsel turizmin kültürel objesi olarak kent ya da kent parçasına ilişkin kültürel ve turistik faaliyetler, toplumsal ve fiziksel ilişkiler dizisi içinde “(...)birçok profesyonel (fotoğrafçılar, gezi kitapları ve rehber yazanlar, yerel meclisler, 'miras endüstrisindeki' uzmanlar, seyahat ajanları, otel sahipleri, tasarımcılar, tur operatörleri, TV'deki gezi programları, turizmi geliştirme görevlileri, mimarlar, planlamacılar, turizm üzerine çalışan akademisyenler vs.) tarafından ayrı ayrı organize edilir" (Urry, 2009, s.252). Kemeraltı son yıllarda yerel yönetimler, özel ve/ya akademik oluşumlar gibi farklı motivasyonlara sahip aktörlerin tarih, kültür, kent kimliği odaklı çalışmaları ve uygulamalarıyla İzmir gündeminde ilk sırada yer almaktadır. Bu anlamda, yeni kentsel turizm için tasarım kültürü önem taşır ve İzmir kenti tasarım kültürünün haritalanmasında, Kemeraltı istisnasız bir önceliğe sahiptir.

İzmir Kemeraltı her zaman orada olup hiçbir zaman tümüyle kavranamayan, gizemli bir keşif alanıdır. Kemeraltı'nı anlamak ve deneyimleri sürekli kılmak için farklı gözlerle bakabilmek gerekir. Keşfetmek; ilham, tesadüf ve sürprizler için yeni kapılar aralamayı gerektirir. Tarihsel, sosyo-kültürel, ekonomik ve mekânsal katmanlarıyla Kemeraltı, kentte keşfedilmeyi ve kentliyle diyaloğa girmeyi bekleyen açık bir yapit gibidir: Deneyimleyenlere her zaman yeni ve tek seferde tümünün kavranması olanaksız pek çok şey söyler. Kente yeni gelmiş bir turist ya da yıllardır İzmir'de yaşan bir kentli olmak fark etmez; buraya ilişkin çok-katmanlı deneyimler, hızlı geçişlerin ve çakışmaların yoğunlaştığı algısal fragmanlar şeklinde ve her seferinde yenidir. İçinde barındırdığı çoklu kimlikleri yansıtan sesleri, renkleri, tatları, kokuları, dokuları, öyküleri ve bellekteki izleri, Kemeraltı'nın gündelik hayat pratiklerinin ve sürprizli karakterinin ayrılmaz parçalarıdır. Zaman ve mekân içinde dağılmış insan ve nesnelere ilişkin farklı duyuların yoğun olarak hissedildiği Kemeraltı, her anlamda ve boyutta alış-verişin ve karşılaşmaların düzlemini oluşturur. Bu düzlemin değerlerini haritalamak, turistik gezi rotalarından farklılaşan kültür-tasarım rotalarının kurgulamak, mimarlık, moda, sanat gibi alanların bilgi üretimi için önem taşıdığı gibi, yeni olası anlamlandırma güzergâhlarına da zemin oluşturur. Bu da, bireysel tanıklıkların ve deneyimlerin çoğalmasını sağlayarak, kent ve tasarım paydasında belleğin ve kültürün sürekliliğine katkıda bulunur. Bununla birlikte, günümüzde kentsel kültürel turizm faaliyetlerinin başarısında ve sürdürülebilirliğinde farklı aktör, kurum ve oluşumların entegrasyonu yanı sıra, faaliyetlerin bu kapsayıcılıkta bir bakışla ele alınması gitgide önem kazanmaktadır.

Kemeraltı'nın mimarlık, moda, tekstil, sanat, zanaat üretimleri ve üretimin kolektif bellekteki izleri kültür ve tasarım paydasında haritalandığında, üretimin mekânlarıaktörleri-deneyimleri-bellekleri gibi dört unsur ortaya çıkar: Diğerlerinden, kent tarihinin somut varlıkları bakımından ayrışan üretim mekânları, tarihsel-işlevsel öneme sahiptir. Kentteki üretim-tüketim pratikleri içinde bir zincirin parçası 
olmadan, bağımsızca ayakta kalabilmiş üretimin aktörleri, geçmişi günümüze taşıyan ekonomik-kültürel istisnalardır. Üretimin deneyimleri, bireysel oldukları kadar, kentliler arasında kültürel-toplumsal köprüler de kurar. Bu mekânlar, aktörler ve deneyimler arasında var olan çoklu ilişkiler ağı, bireyden tüm kentlilere, geçmişten geleceğe doğru örülerek kolektif belleği şekillendirir. Bu açıdan üretimin belleği, kolektif belleğin bir parçası olarak, tarihsel-ekonomikkültürel-toplumsal ilmekleri atar. Alternatif rotalarda yapılan geziler kentlilere, içinden geçip gittikleri bu mekânları -içindeki nesneler, üretim pratikleri, deneyimler ve onlara ilişkin bellekteki izlerle birlikte görünür hale getirir.

Kent turizmi için pazarlama stratejileri, iletişim, yaratıcılık, bilginin, deneyimin ve teknolojinin ziyaretçilere aktarımı gibi konulardaki öneminin ötesinde, kent içi alternatif gezi güzergâhlarına olanak sağlayacak türden haritalama pratikleri, hem yerli hem de yabancı ziyaretçilerin gündelik hayatta kentlilik deneyimi, kent kimliği, kent ve üretim belleği üst başlıkları altında ayrıntılanabilecek tasarıma ait farklı alanların üretim pratikleri ve deneyimlerinin kaydedilmesi, paylaşılması ve sürdürülmesi açılarından önemlidir. Yeni kültür turizmi ve yeni kentsel turizm paydasında Kemeraltı -İzmir kenti ve turizmi için yüzyıllardır olduğu gibi- bugün ve gelecekte de önemini koruyacaktır.

\section{Kaynakça}

Aksatan, M. (2014). Sürdürülebilir turizm ve doğal miras. Kozak, M. (Ed.). Sürdürülebilir turizm kavramlar ve uygulamalar içinde (s.30-44). Ankara: Detay Yayıncılık.

Aksoy, Y. (1992). Guide to İzmir rehberi. İzmir: ADR Reklam Hizmetleri.

Allinson, K. (2009). London's contemporary architecture: A map-based guide (5. basım). Oxford: Architectural Press.

Atilla, A. N. (2001). Tarihten günümüze İzmir mutfağı. İzmir: İzmir Büyükş̧ehir Belediyesi Kent Kitaplığı Yayınları.

Aydoğan, M. (2001). Kent kimliğinin ortaya çıkarılması amacıyla kentsel tasarım rehberlerinin kullanımı: Kemeraltı örneği (Yayınlanmamış yüksek lisans tezi). Dokuz Eylül Üniversitesi Fen Bilimleri Enstitüsü, Şehir ve Bölge Planlama Anabilim Dalı, İzmir.

Cultural mapping. (2019). UNESCO Bangkok. Erişim adresi: https:// bangkok.unesco.org/content/cultural-mapping

Cultural Routes - Routes4U Project. (t.y.). Council of Europe, European Union. Cultural routes mapping. Erişim adresi: https://pjp-eu.coe. int/en/web/cultural-routes-and-regional-development/mapping

Duxbury, N., Garrett-Petts, W. F. ve MacLennan, D. (2015). Cultural mapping as cultural inquiry: Introduction to an emerging field of practice. Duxbury, N., Garrett-Petts, W. F. ve MacLennan, D. (Ed.). Cultural mapping as cultural inquiry içinde (s.1-42). New York, Londra: Routledge.

Ecemiş Kılıç, S. ve Aydoğan, M. (2006). Katılımcı bir kentsel koruma projesi: İzmir - Kemeraltı tarihi kent merkezi. Ege Coğrafya Dergisi, 15, 61-71.

Ege Derneği. (2011). İzmir kültür turizmi sektör araştırması tespit ve öneriler. Erişim adresi: http://egedernegi.org.tr/downloads/ pdf1.pdf

Eräranta, K., Leino, T., Seppälä, T., Vina , S., ve Timonen, E. (2016). Mapping the Pig Tale Journey: A multidisciplinary design framework for cultural mapping in an old Abattoir. City, Culture and Society, 7(1), 25-33.

Ernsten, C. (2014). Beyroutes, A Guide to Beirut (4. basım). Lübnan: Archis.

Evans, G. (2001). Cultural planning: An urban renaissance? Londra: Routledge.

Evans, G. ve Foord, J. (2008). Cultural mapping and sustainable communities: Planning for the arts revisited. Cultural Trends, 17(2), 65-96.

Franke-Höltzermann, C. (2006). Neues Stuttgart architektur. Berlin: Verlaghaus Braun.

Freitas, R. (2016). Cultural mapping as a development tool. City, Culture and Society, 7(1), 9-16.

Gadamer, H-G. (1979). Truth and Method. (W. Gled-Doepel, Çev.). (1. basım 1960). Londra: Sheed and Ward.

Geçer, F. (1999). The design of information elements in urban areas: A case study in İzmir, Kemeraltı (Yayınlanmamış yüksek lisans tezi). İzmir Yüksek Teknoloji Enstitüsü Fen Bilimleri Enstitüsü, Şehir ve Bölge Planlama Anabilim Dalı, İzmir.

Gezi Rehberi. (t.y.). İzmir Kültür ve Turizm Dergisi. Erişim adresi: http://izmirdergisi.com/tr/turizm/gezi-rehberi

Görmüş, S. (2018, 3 Ocak). Kültürel peyzaj değerlerini korumak için yeni bir yaklaşım: Kültürel rotalar. Plant Peyzaj ve Süs Bitkiciliği Dergisi. Erişim adresi: http://www.plantdergisi.com/doc-drsevgi-gormus/kulturel-peyzaj-degerlerini-korumak-icin-yenibir-yaklasim-kulturel-rotalar.htm

Güner, D. (Ed.). (2005). İzmir mimarlık rehberi 2005. Mimarlar Odası İzmir Şubesi. İstanbul: Mas Matbaası. 
Hakkında. (t.y.). $4 T$ (Tasarım ve Tasarım Tarihi Topluluğu) Derneği. Erişim adresi: http://www.4t.org.tr/About_tr.html

Hannam, K. (2009), The end of tourism? Nomadology and the mobilities paradigm. Tribe, J. (Ed.), Philosophical Issues in Tourism içinde (s. 101-113). Bristol: Channel View.

Haubrich, R., Hoffmann, H. W. ve Meuser, P. (2006). Berlin - The architecture guide. Berlin: Braun Publishing.

İncedayı, D. (Ed.). (2005, Eylül). Dosya: Mimarlık, kültür ve turizm. Mimar.ist Dergisi, 17, 33-71.

İzmir Akdeniz Akademisi. (2019). Etkinlikler. Erişim adresi: https:// www.izmeda.org/?page_id=320\#content

İzmir Büyükşehir Belediyesi İzmir Tarih Proje Merkezi. (t.y.). İzmir Tarih. Erişim adresi: http://www.izmirtarih.com.tr/

İzmir İl Kültür ve Turizm Müdürlüğü. (2000). İzmir turizm envanteri. İzmir: İzmir Valiliği Kültür Yayınları.

İzmir Konak Belediyesi (2009). İzmir'i iyileştirmek: Kent yenileme çalışmaları 2005-2009. İzmir: Konak Belediyesi Yayınları.

İzmir rehberi. (t.y.). İzmir Ticaret Odası. Erişim adresi: http://www. izto.org.tr/tr/izmir-rehberi

İzmir kültür çalıştayı. (2009). İzmir Büyükşehir Belediyesi. Erişim adresi: https://www.izmirelele.com/Extras/file/kulturcalistayi. pdf

İzmir'de bir gün - Turizm rehberi. (t.y.). İzmir Büyükşehir Belediyesi. Erişim adresi: https://www.izmir.bel.tr/tr/Yayin/157/227\#dergi/ sayfa1

Karpat, G. K. (2009). Tarihsel alanlarda sözlü tarih bilgisine dayalı kentsel tasarım kriterlerinin oluşturulması; Kemeraltı Anafartalar Caddesi (İzmir) (Yayınlanmamış yüksek lisans tezi). Dokuz Eylül Üniversitesi Fen Bilimleri Enstitüsü, Şehir ve Bölge Planlama Anabilim Dalı, İzmir.

Kayın, E. (Ed.). (2002, Mart). Dosya: İzmir'in tarihsel kent mekânları için yeni vizyonlar. Ege Mimarlık, 43, 4-45.

Kemeraltı. (t.y.). T.C. Kültür ve Turizm Bakanlığı, İzmir İl Kültür ve Turizm Müdürlüğü. Erişim adresi: http://www.izmirkulturturizm. gov.tr/TR-77370/kemeralti.html

Kemeraltı dünya mirası olsun (t.y.). Yeni Asır Gazetesi. Erişim adresi:https://www.yeniasir.com.tr/izmir/2015/09/29/ kemeralti-dunya-mirasi-olsun

Kemeraltı rotası. (t.y.). İzmir Guide. Erişim adresi: http://www. izmirguide.com/kemeralti-rotasi

Kemeraltı'ndan Kültürpark’a tasarım rotası (t.y.). İzmir İyi Tasarım
Günleri_I. Erişim adresi: http://www.izmir.com.tr/Pages/Art/ OtherDetail.aspx?otherid $=34192$

Kent rehberi. T.C. Kültür ve Turizm Bakanlığı İzmir İl Kültür ve Turizm Müdürlüğü. (t.y.). Erişim adresi: http://www.izmirkulturturizm. gov.tr/TR-77343/izmir-rehberi.html

KNK Dergi. (t.y.). İzmir Konak Belediyesi. Erişim adresi: http://www. konak.bel.tr/sayfa/knk-dergi

Kültür turizmi. (2018). T.C. Kültür ve Turizm Bakanlığı, İzmir İl Kültür ve Turizm Müdürlüğ̈u. Erişim adresi: http://www.izmirkulturturizm. gov.tr/TR-92447/kultur-turizmi.html

Lefebvre, H. (1991a). The critique of everyday life (Critique de la vie quotidienne), cilt 1 (J. Moore, Çev.). (1. basım 1947). London, New York: Verso.

. (1991b). The production of space (La production de l'espace) (D. Nicholson-Smith, Çev.). (1. basım 1974). Oxford: Basil Blackwell.

(2014). Toward an architecture of enjoyment (Vers une architecture de la jouissance). Stanek, t. (Ed.), (R. Bononno, Çev.), Minneapolis: University of Minnesota Press.

Li, M., Wu, B. ve Cai, L. (Nisan 2008). Tourism development of world heritage sites in China, a geographical perspective. Tourism Management, 29(2), 308-319.

Longley, A. ve Duxbury, N. (2016). Introduction: Mapping cultural intangibles. City, Culture and Society, 7, 1-7.

Loulanski, T. ve Loulanski, V. (Mart 2011). The sustainable integration of cultural heritage and tourism: A meta study. Journal of Sustainable Tourism, 19(7), 837-862.

Maitland, R. (2008). Conviviality and everyday life: The appeal of new areas of London for visitors. International Journal of Tourism Research, 10(1), 15-25.

(2010). Everyday life as a creative experience in cities. International Journal of Culture, Tourism and Hospitality Research, 4(3), 176-185.

Poria, Y., Butler, R. ve Airey, D. (Ocak 2003). The core of heritage tourism. Annals of Tourism Research, 30(1), 238-254.

Radović, D. (2016). Measuring the non-measurable: On mapping subjectivities in urban research. City, Culture and Society, 7(1), 17-24.

Recommendations on tourism statistics. (1994). UNWTO Statistical papers. Madrid, İspanya. Erişim adresi: https://www.e-unwto. org/doi/pdf/10.18111/9789211613629

Richards, G. (1996). Cultural tourism in Europe. Wallingford: CABI. 
(2003). What is cultural tourism? Van Maaren, A. (Ed.). Erfgoed voor toerisme. Weesp: Nationaal Contact Monumenten içinde (s.30-44). Erişim adresi: https://www.researchgate.net/ publication/324031354_What_is_Cultural_Tourism

(2019). Kültür turizmi: Son araştırmalar ve eğilimlere dair bir inceleme. Özdemir, N. ve Öger, A. (Ed.). (M. Yeniasır, Çev.). Kültürel miras yönetimi içinde (s.583-614). Ankara: Grafiker Yayınları.

Rotalar. (t.y.). İzmir Guide. Erişim adresi: http://www.izmirguide. com/rotalar

Saban, D., Karaman, F., Erman, O. ve Durukan, İ. (Ed.). (2006). Adana mimarlık rehberi 1900-2005. Mimarlar Odası Adana Şubesi. Adana: Alev Dikici.

Smith, N. (2006). Yeni küresellik, yeni şehircilik: Küresel kentsel strateji olarak soylulaştırma. (İ. Urkun-Bowe ve İ. Gündoğdu, Çev.). Planlama, 2, 13-27.

Stewart, S. (2007). Cultural mapping toolkit. Vancouver: Creative City Canada and 2010 Legacies Now. Erişim adresi: https://www. creativecity.ca/database/files/library/cultural_mapping_toolkit. pdf

Şala, D. (2013). Kentsel kimlik bağlamında kentsel tasarım rehberlerinin irdelenmesi (İzmir-Kemeralt tarihi kent merkezi örneği) (Yayınlanmamış yüksek lisans tezi). Mimar Sinan Güzel Sanatlar Üniversitesi Fen Bilimleri Enstitüsü, Şehir ve Bölge Planlama Anabilim Dalı, İstanbul.

Tarihi Kemeraltı Çarşısı. (t.y.). İzmir Kalkınma Ajansı. Erişim adresi: http://www.visitizmir.org/tr/sayfa/tarih/tarihi-yerler/sehirmerkezindeki-tarihi-yapilar/tarihi-kemeralti-carsisi-780497

TARKEM. (t.y.). Kültürel projeler. Erişim adresi: http://www.tarkem. com/proje/

Taşkıran, H. K. (2008). Kemeraltı'nın İzmir'i: Tarih kültür ve gezi rehberi. İzmir: Tepekule Kitaplığı Yayınları.

T.C. İzmir Valiliği İl Kültür ve Turizm Müdürlüğü. (2006). İzmir turizm sempozyumu. İzmir: İzmir Valiliği Kültür Yayınları.

Tekeli, İ. (2017). İzmir Tarih projesi tasarım stratejisi raporu. (5. basım). Kutlu, G., Çalışkan, M., Akyıldız, G., Kaplan, Ç. D. ve Korkmaz, A. (Ed.). İzmir: Dinç Ofset.

Timothy, D. J. ve Boyd, S. W. (2001). Heritage tourism (Themes in tourism). Essex: Prentice Hall.

Tourism at world heritage sites: Challenges and opportunities. (2013). UNWTO conferences and seminars. International tourism seminar. 26 Mart 2013. Çeşme, İzmir, Türkiye. Erişim adresi: https://www.e-unwto.org/doi/pdf/10.18111/9789284416608
Turistik gezi rotası hazırlıyoruz. (t.y.). İzmir Büyükşehir Belediyesi. Erişim adresi: https://www.izmir.bel.tr/tr/Projeler/1456/4

Tüm Rotalar, (2017). Kültür Rotaları Derneği. Erişim adresi: http:// cultureroutesinturkey.com/tr/tum-rotalar/

Türk Dil Kurumu. (t.y.). Kültür. Türk Dil Kurumu Güncel Türkçe Sözlük. Erişim adresi: https://sozluk.gov.tr/?kelime=

UNESCO database of national cultural heritage laws. (2003). UNESCO. Erişim adresi: http://www.unesco.org/new/en/culture/ themes/illicit-trafficking-of-cultural-property/unesco-databaseof-national-cultural-heritage-laws/

UNESCO somut olmayan kültürel miras. (t.y.). T.C. Kültür ve Turizm Bakanlığı İzmir İl Kültürr ve Turizm Müdürlüğü. Erişim adresi: http://www.izmirkulturturizm.gov.tr/TR-90964/unesco-somutolmayan-kulturel-miras.html

Urry, J. (2007). Mobilities. Cambridge: Polity.

(2009). Turist bakışı (E. Tataroğlu ve İ. Yıldız, Çev.). İstanbul: Ayrıntı Yayınları.

_. (2015). Mekânları tüketmek (R. G. Öğdül, Çev.). İstanbul: Ayrıntı Yayınları.

Ürük, Y. (2009). Adım adım İzmir ve çevresi - İzmir guide. İzmir: Yakın Kitap.

Yakıcı, N. (2018). Urban regeneration contexts in historical city centers: Izmir, Kemeralti case (Yayınlanmamış yüksek lisans tezi). İzmir Katip Çelebi Üniversitesi Fen Bilimleri Enstitüsü, Kentsel Dönüşüm Anabilim Dalı, İzmir.

Yarımada İzmir: Gezi rotaları. (t.y.). İzmir Büyükșehir Belediyesi. Erişim adresi: http://rota.yarimadaizmir.com/tr/Anasayfa

Yentürk, N. (2018). Ayaküstü İzmir sokak ve fırın lezzetleri. İstanbul: Oğlak Yayıncılık.

Zeybek Çetin, R. (2012). Tarihi kent merkezlerinde yeniden canlandırma politikaları üzerine değerlendirme, İzmir Kemeraltı örneği (Yayınlanmamış yüksek lisans tezi). Dokuz Eylül üniversitesi Fen Bilimleri Enstitüsü, Kentsel Tasarım Anabilim Dalı, İzmir. 